\title{
Perbandingan Estimasi Produksi Metode Sensus Buah Hitam dengan Metode Indeks Musiman
}

\author{
Comparison of Production Estimates Using the Black Bunch Census Method with the \\ Seasonal Index Method \\ Amar Makrup*, Jamaluddin, Jumri \\ ${ }^{1}$ Politeknik Pertanian Negeri Samarinda, Kampus Gunung Panjang, JI. Samratulangi, Samarinda, \\ Indonesia \\ *Corresponding Author: Amar10cadall@gmail.com
}

\begin{abstract}
BBC (Black Bunch Census) dan Estimasi Produksi Dengan Metode Seasonal Index (Indeks Musiman) adalah dua metode yang dapat digunakan dalam menentukan estimasi produksi tandan buah segar kelapa sawit dimasa yang akan datang. Tujuan dari penelitian ini adalah untuk mengetahui metode estimasi manakah yang tingkat akurasi estimasi produksinya lebih tinggi atau mendekati realisasi. Penelitian ini menggunakan data primer, yaitu data yang diambil di tiga blok yang berbeda yaitu A 18, A 19, dan A 20, di mana sampel diambil dari setiap blok sebanyak $10 \%$ dari total pokok untuk perhitungan black bunch census, sedangkan untuk estimasi produksi dengan metode seasonal index hanya menggunakan jumlah pokok pada Blok tersebut serta menggunakan tabel standar produksi berdasarkan klasifikasi lahan dan umur tanaman sebagai perhitungan dasar dalam menentukan estimasi produksi. Hasil penelitian ini menunjukkan bahwa penggunaan metode estimasi produksi yang dikombinasikan dengan seasonal index memberikan hasil yang lebih akurat dari pada metode estimasi produksi menggunakan black bunch census.
\end{abstract}

Kata Kunci: Estimasi Produksi, Black Bunch Census, Seasonal Index, Standard Produksi Berdasarkan Klasifikasi Lahan dan Umur Tanaman.

\begin{abstract}
BBC (Black Bunch Census) and Production Estimation Using the Seasonal Index Method are two methods that can be used to determine the estimated production of oil palm fresh fruit bunches in the future. The purpose of this study is to find out where the estimated production estimates are higher or closer to realization. This study uses primary data, namely data taken in three different blocks, namely A 18, A 19, and A 20, where samples are taken from each block as much as $10 \%$ of the total principal for the calculation of the black bunch census, while for production estimation the method the seasonal index only uses the amount of production in the block and uses a standard table based on land classification and plant age as a basic calculation in determining production estimates. The results of this study indicate that the use of the production estimation method combined with the seasonal index gives more accurate results than the production estimation using the black bunch census.
\end{abstract}

Keywords: Production Estimation, Black Bunch Census, Seasonal Index, Production Standards Based on Land Classification and Plant Age.

\section{PENDAHULUAN}

Produktivitas kelapa sawit perlu diketahui agar dapat disusun suatu sistem pengelolaan perkebunan dengan tingkat produktivitas yang tinggi sehingga mampu bersaing dipasar dunia. Produktivitas merupakan suatu ukuran yang menyatakan bagaimana baiknya sumber daya diatur dan dimanfaatkan untuk mencapai hasil yang optimal dari suatu produksi. Agar produksi tercapai diperlukan suatu sistem produksi yang dikelola dengan baik. Sistem produksi yang perlu dilakukan contohnya yaitu perencanaan, perbaikan infrastruktur dan pengawasan produksi. Dalam rangka pengawasan produksinya, sebuah perusahaan kelapa sawit telah menerapkan 
berbagai metode, seperti pengawasan dan perencanaan melalui hasil dari perhitungan Estimasi produksi tandan buah segar kelapa sawit. Peranan estimasi produksi sangatlah penting karena estimasi produksi dari tandan buah segar akan digunakan dalam menentukan kebutuhan sumber daya dimasa depan seperti menghitung kebutuhan transportasi, tenaga kerja dan target produksi.

Dalam transportasi, hasil dari estimasi produksi akan digunakan untuk menghitung keperluan seperti kebutuhan kendaraan angkutan buah, supir, tenaga bongkar muat, bahan bakar dan lain-lain. Sama halnya dengan kebutuhan transportasi estimasi produksi juga berperan penting dalam menentukan kebutuhan tenaga kerja yang diperlukan seperti kebutuhan tenaga kerja panen, mandor panen, kerani panen, beserta upahnya. Peranan estimasi produksi lainnya yaitu digunakan dalam menentukan target tahunan, kwartal, bulanan, dan harian untuk tiap-tiap afdeling. Dalam menentukan estimasi produksi diperlukan metode yang diharapkan menghasilkan tingkat akurasi yang tinggi.

Salah satu metode umum estimasi produksi yang sering digunakan adalah metode BBC (Black Bunch Census). Dilakukannya estimasi produksi menggunakan BBC (Black Bunch Census) ternyata masih terdapat masalah, yaitu berupa selisih yang cukup besar pada rentang perperiodenya. Karena masih kurangnya tingkat akurasi dari metode BBC (Black Bunch Census) bila dibandingkan dengan realisasi, tentu saja masih ada cara lain untuk melakukan estimasi produksi, seperti metode estimasi produksi yang di kombinasikan dengan seasonal index. Dari kedua cara diatas masih belum diketahui cara mana yang lebih akurat, karena hampir setiap perusahaan memiliki metode dan cara masing-masing dalam menentukan estimasi produksi mereka. penentuan metode estimasi produksi sangatlah penting, karena akan berpengaruh pada tingkat akurasi, pengambilan keputusan dan perancanaan di kemudian hari.

Berdasarkan uraian latar belakang masalah diatas, maka peneliti merumuskan permasalahan dalam penelitian ini sebagai berikut : "Bagaimana perbandingan metode estimasi produksi dengan metode BBC
(Black Bunch Census) dan seasonal index serta bagaimana tingkat akurasi dua metode tersebut dalam menentukan estimasi produksi". Agar setiap masalah yang dibahas dalam penelitian ini mencapai target dan memberikan arah yang jelas, maka penulis membatasi ruang linkup yang di teliti, diantaranya :"Melakukan BBC (Black Bunch Census) di lapangan serta memanfaatkan data seasonal index untuk dikombinasikan dengan standard produksi berdasarkan klasifikasi lahan dan umur tanaman, lalu melakukan perbandingan antara kedua metode tersebut".

Tujuan dari penelitian ini adalah untuk mengetahui tingkat akurasi metode BBC (Black Bunch Census) dan metode seasonal index dalam menentukan estimasi produksi tandan buah segar. Hasil yang diharapkan dari penelitian ini adalah dapat membantu perusahaan perkebunan dalam menentukan metode yang terbaik untuk estimasi produksi tandan buah segar, sehingga perencanaan, serta pengawasan dapat tertata dengan baik.

\section{METODE PENELITIAN}

Penelitian ini dilaksanakan di PT. Tritunggal Sentra Buana, Desa Saliki, Kecamatan Muara Badak, Kabupaten Kutai Kartanegara pada bulan September sampai dengan bulan Desember 2020.

Alat yang digunakan dalam penelitian ini di antaranya adalah pulpen, tongkat sensus, dan form sensus, sedangkan untuk bahan yang digunakan dalam penelitian ini diantaranya adalah data standard produksi berdasarkan kelas lahan dan umur tanaman, histori produksi tiga tahun terakhir, dan data produksi aktual selama empat bulan.

Pengumpulan Data BBC (Black Bunch Census) Penelitian ini menggunakan form sensus untuk pengambilan sampel pada metode BBC (Black Bunch Census), adapun teknis kerja sensus adalah sebagai berikut:

a. Sensus ini mengambil sampel pada baris 10 dan kelipatan 10 karena sensus ini melibatkan intensitas sampling $10 \%$ di setiap bloknya., 10 contohnya : 10, 20, 30, 40 dan seterusnya.

b. Egrek sensus dikaitkan pada salah satu janjang (penanda awal perhitungan) dan dilanjutkan ke semua janjang pada pokok tersebut. 
c. Untuk menghitung janjang yang akan dimasukkan kedalam form sensus yaitu dengan cara menghitung buah hitam yang telah terlepas sempurna dari seludang.

d. Buah yang telah berubah warna ke merahan ataupun kuning tidak dihitung.

e. Kemudian hasil hitungan dimasukkan ke dalam form sensus.

Data dari form sensus kemudian dilakukan rekapitulasi, lalu hasil data tersebut disebarkan ke 4 bulan yang akan datang dimana penyebarannya dilakukan berdasarkan persentase histori produksi selama 3 tahun terakhir pada empat bulan tersebut, hasil dari masing-masing estimasi produksi akan dikurangkan dengan realisasi untuk mengetahui selisih dan tingkat akurasi metode BBC (Black Bunch Census)

Pengumpulan Data Metode Seasonal Index (Indeks Musiman) Berbeda dengan metode Black Bunch Census yang melakukan observasi secara langsung di lapangan. Pada metode estimasi produksi yang dikombinasikan seasonal index (Indeks Musiman) jumlah janjang perpokok, berat janjang rata-rata dan jumlah produksi TBS (Tandan Buah Segar) dalam satu Ha/Thn sudah diketahui serta ditentukan dari tabel standar produksi buah berdasarkan Kelas lahan dan umur tanaman, dan menggunakan klasifikasi lahan IV, dimana klasifikasi ini adalah jenis tanah pada umumnya di Kalimantan (Firmansyah, 2014).Sesuai dengan tempat dimana penelitian ini dilakukan.

Kemudian dari data tersebut diperoleh lah data estimasi produksi perbulan akan tetapi estimasi yang dihasilkan belumlah realistis sehingga perlu dikombinasikan dengan data seasonal index, nilai yang dihasilkan berupa perhitungan data historis produksi bulanan selama tiga tahun terakhir.

Pengolahan Data BBC (Black Bunch Census) Data dari hasil sensus di rekap kemudian dilakukan perhitungan dengan 2 persamaan yaitu:

a. Persamaan satu untuk menghitung ratarata tandan perpokok dengan cara: Janjang Periksa Pokok Periksa

b. Persamaan kedua untuk taksiran hasil per blok dengan cara :

Rata-rata tandan/pokok x BJR x jumlah pokok/Blok
Hasil estimasi tonase atau taksiran tonase per blok kemudian disebar berdasarkan persentase histori produksi selama tiga tahun terakhir untuk mencari estimasi perbulannya.

Pengolahan Data Seasonal Index (Indeks Musiman) Perhitungan estimasi produksi dengan metode Seasonal Index (Indeks Musiman) dapat dilakukan dengan menggunakan persamaan-persamaan sebagai berikut (Mangoensoekardjo \& Semangun, 2008):

a. Persamaan pertama untuk menghitung jumlah tandan per bulan

jumlah tandan/pokok x jumlah pokok/blok Jumlah bulan dalam satu tahun

b. Persamaan kedua untuk menghitung taksiran produksi per bulan

jumlah tandan per bulan x BJR

taksiran produksi perbulan yang dihasilkan dari persamaan diatas tidak akan realistis dan tingkat akurasinya sangat rendah, sehingga perlu dikalikan dengan nilai dari seasonal index (indeks musiman), cara menentukan nilai seasonal index yaitu dengan cara mencari nilai rata-rata produksi aktual selama tiga tahun, kemudian dibagi dengan nilai rata-rata dari produksi aktual dari keseluruhan bulan.

Perbandingan Estimasi Produksi Metode Black Bunch Census Dan Seasonal Index. Hasil perhitungan estimasi produksi dalam menentukan selisih atau keakuratan dua metode tersebut. tidak akan seratus persen akurat (Hudori dan Sugiyatno,2016). Untuk membandingkan kedua metode tersebut membutuhkan selisih dari masingmasing metode dengan realisasi dengan melakukan pengurangan antara realisasi dengan estimasi produksi masing-masing metode. Kemudian untuk mencari persentase kesalahan dengan cara membagi selisih dengan realisasi kemudian dikali seratus, adapun persamaannya sebagai berikut :

$$
\frac{\text { Selisih }}{\text { Realisasi }} \times 100 \%
$$

\section{HASIL DAN PEMBAHASAN}

Pada penelitian ini disajikan datadata yang diperoleh selama penelitian di PT. Tritunggal Sentra Buana yang dijadikan sebagai lokasi penelitian. Hasil peneliti 
berupa data priemer dan data sekunder yang diperoleh secara langsung dari lapangan kemudian di analisa dalam bentuk penelitian komparasi. Penelitian ini dilakukan pada bulan September untuk memperkirakan hasil panen pada bulan Oktober-Januari. Penelitian ini dilakukan pada 3 blok yang berbeda yaitu blok A18,
A19, dan $A 20$, sedangkan untuk tahun tanam dari ke tiga blok tersebut berada ditahun yang sama yaitu 2006 .

Hasil estimasi dari metode black bunch census dapat dilihat pada tabel 1.

Tabel 1. Estimasi produksi metode black bunch cencus

\begin{tabular}{|c|c|c|c|c|c|}
\hline Blok & Bulan & $\begin{array}{c}\text { Hasil Estimasi } \\
(\mathrm{Kg})\end{array}$ & $\begin{array}{c}\text { Realisasi } \\
(\mathrm{Kg})\end{array}$ & $\begin{array}{l}\text { Selisih } \\
(\mathrm{Kg})\end{array}$ & $\%$ \\
\hline \multirow[t]{4}{*}{ A 18} & Okto & $66.536,20$ & 55.408 & -11.128 & $-20,1$ \\
\hline & Nov & $43.430,90$ & 46.704 & 3.273 & 7,0 \\
\hline & Des & $35.265,90$ & 41.719 & 6.453 & 15,5 \\
\hline & Jan & $28.490,70$ & 31.795 & 3.304 & 10,4 \\
\hline \multicolumn{2}{|c|}{ Rata-rata } & 43430,9 & 43906,5 & 476 & 1,1 \\
\hline \multirow[t]{4}{*}{ A 19} & Okto & $61.772,90$ & 54.292 & $-7.480,9$ & $-13,8$ \\
\hline & Nov & $38.903,80$ & 40.299 & 1.395 & 3,5 \\
\hline & Des & 22.768 & 35.625 & 12.857 & 36,1 \\
\hline & Jan & $26.185,30$ & 25.236 & -949 & $-3,8$ \\
\hline \multicolumn{2}{|c|}{ Rata-rata } & 37407,5 & 38863 & 1.456 & 3,7 \\
\hline \multirow[t]{4}{*}{ A 20} & Okto & 74.352 & 64.184 & -10.168 & $-15,8$ \\
\hline & Nov & $25.971,60$ & 39.159 & 13.187 & 33,7 \\
\hline & Des & $29.121,30$ & 30.675 & 1.554 & 5,1 \\
\hline & Jan & $23.022,60$ & 20.786 & -2.237 & $-10,8$ \\
\hline \multicolumn{2}{|c|}{ Rata-rata } & 38.117 & 36.418 & -1.699 & $-4,7$ \\
\hline
\end{tabular}

$(-)$ nilai minus berarti realisasi tidak dapat mencapai nilai estimasi dari metode BBC

$(+)$ realisasi dapat mencapai nilai estimasi dari metode BBC

Dari analisis data yang telah dilakukan diperoleh hasil estimasi masing-masing Blok yaitu, untuk Blok A18 pada bulan Oktober menghasilkan tonase sebesar $66.536,4 \mathrm{Kg}$, November sebesar 43.430,9 $\mathrm{Kg}$, Desember sebesar $35.265,9 \mathrm{Kg}$, dan Januari sebesar $28.490,7 \mathrm{Kg}$. Rata-rata kesalahan perbloknya sebesar 1,1 \% dengan rentang kesalahan perbulan mencapai $-20,2 \%$ sampai dengan 15,5\% dan untuk selisih tonase berkisar antara 11.128 Kg sampai dengan 6.453,1 Kg.

Blok A19 estimasi yang dihasilkan untuk tonase perbulannya yaitu pada bulan Oktober sebesar $61.772,9 \mathrm{Kg}$, November sebesar 38.903,8 Kg, Desember sebesar $22.768 \mathrm{Kg}$ dan Januari sebesar 26.185,3 Kg. Rata-rata kesalahan perbloknya mencapai 3,7 \%, Dengan rentang kesalahan perbulan mencapai $-13,8 \%$ sampai dengan 36,1 \% dan untuk selisih tonase berkisar antara $-7.480,9 \mathrm{Kg}$ sampai dengan $12.857 \mathrm{Kg}$

Untuk Blok A20 estimasi yang dihasilkan untuk tonase perbulannya yaitu pada bulan Oktober sebesar $74.352 \mathrm{Kg}$, November sebesar 25.971,6 Kg, Desember sebesar 29.121,3 Kg dan Januari sebesar 23.022,6 Kg. Rata-rata kesalahan perbloknya mencapai $-4,7 \%$, Dengan rentang kesalahan perbulan mencapai $15,8 \%$ sampai dengan $33,7 \%$ dan untuk selisih tonase berkisar antara $-19.301 \mathrm{Kg}$ sampai dengan $13.187,4 \mathrm{Kg}$.

Hasil estimasi dari metode seasonal index dapat dilihat pada tabel 2. 
Tabel 2. Estimasi Produksi Metode Seasonal Index

\begin{tabular}{|c|c|c|c|c|c|}
\hline Blok & Bulan & $\begin{array}{c}\text { Hasil } \\
\text { Estimasi } \\
(\mathrm{Kg})\end{array}$ & $\begin{array}{l}\text { Realisasi } \\
\text { (Kg) }\end{array}$ & $\begin{array}{l}\text { Selisih } \\
\text { (Kg) }\end{array}$ & $\%$ \\
\hline \multirow[t]{4}{*}{ A 18} & Okto & 70.797 & 55.408 & -15.389 & $-27,8$ \\
\hline & Nov & 45.935 & 46.704 & 769 & 1,6 \\
\hline & Des & 37.663 & 41.719 & 4.056 & 9,7 \\
\hline & Jan & 30.454 & 31.795 & 1.341 & 4,2 \\
\hline \multicolumn{2}{|c|}{ Rata-rata } & 46212,3 & 43906,5 & -2.306 & $-5,3$ \\
\hline \multirow[t]{4}{*}{ A 19} & Okto & 59.912 & 54.292 & -5.620 & $-10,4$ \\
\hline & Nov & 39.573 & 40.299 & 726 & 1,8 \\
\hline & Des & 26.166 & 35.625 & 9.459 & 26,6 \\
\hline & Jan & 26.738 & 25.236 & -1.502 & -6 \\
\hline \multicolumn{2}{|c|}{ Rata-rata } & 38097,3 & 38863 & 766 & 2 \\
\hline \multirow[t]{4}{*}{ A 20} & Okto & 62.481 & 64.184 & 1.703 & 2,7 \\
\hline & Nov & 39.462 & 39.159 & -303 & $-0,8$ \\
\hline & Des & 29.519 & 30.675 & 1.156 & 3,8 \\
\hline & Jan & 23.290 & 20.786 & -2.504 & -12 \\
\hline \multicolumn{2}{|c|}{ Rata-rata } & 38.688 & $36.417,80$ & -2.270 & $-6,2$ \\
\hline
\end{tabular}

(-) nilai minus berarti realisasi tidak dapat mencapai nilai estimasi dari metode seasonal index.

(+) realisasi dapat mencapai nilai estimasi dari metode seasonal index.

Dari analisis data yang dilakukan diperolehlah hasil estimasi produksi masing-masing blok yaitu untuk blok $\mathrm{A} 18$ pada bulan Oktober estimasi yang dihasilkan mencapai $70.797 \mathrm{Kg}$, November sebesar $45.935 \mathrm{Kg}$, Desember sebesar $37.663 \mathrm{Kg}$, dan Januari sebesar $30454 \mathrm{Kg}$. Rata-rata tingkat kesalahan perbloknya mencapai $-5,3 \%$ dengan rentang kesalahan perbulan mencapai $-27,8 \%$ sampai dengan 9,7 \% dan untuk selisih tonase berkisar antara $-15.389 \mathrm{Kg}$ sampai dengan $4.056 \mathrm{Kg}$.

Blok A 19 pada bulan Oktober estimasi yang dihasilkan mencapai $59.912 \mathrm{Kg}$, November sebesar $39.573 \mathrm{Kg}$, Desember sebesar $26.166 \mathrm{Kg}$ dan Januari sebesar $26.738 \mathrm{Kg}$. Rata-rata tingkat kesalahan perbloknya mencapai $2 \%$, dengan rentang kesalahan perbulan mencapai $-10,4 \%$ sampai dengan 26,6 \% dan untuk selisih tonase berkisar antara $-5.620 \mathrm{Kg}$ sampai dengan $9.459 \mathrm{Kg}$.

Blok A 20 pada bulan Oktober estimasi yang dihasilkan mencapai $62.481 \mathrm{Kg}$,
November sebesar $39.462 \mathrm{Kg}$, Desember sebesar $29.519 \mathrm{Kg}$ dan Januari sebesar $23.290 \mathrm{Kg}$. Rata-rata tingkat kesalahan perbloknya mencapai $-6,2 \%$, dengan tingkat kesalahan perbulan mencapai $-12 \%$ sampai dengan 3,8 \% dan untuk selisih tonase berkisar antara $-2.504 \mathrm{Kg}$ sampai dengan $1.156 \mathrm{Kg}$.

\section{KESIMPULAN}

1. Berdasarkan hasil dan pembahasan tingkat persentase kesalahan yang dihasilkan oleh estimasi produksi dengan metode black bunch census di PT. Tritunggal Sentra Buana adalah sebesar $2,1 \%$.

2. Berdasarkan hasil dan pembahasan tingkat persentase kesalahan yang dihasilkan oleh estimasi produksi dengan metode seasonal index di PT. Tritunggal Sentra Buana adalah sebesar $-1,3 \%$. 
3. Dari kedua metode yang telah dilakukan menunjukkan hasil estimasi produksi dengan metode seasonal index lebih tinggi tingkat akurasinya dibandingkan metode black bunch cencus.

4. Berdasarkan batas toleransi yang ditetapkan perusahaan untuk metode estimasi yaitu $\pm 5 \%$, maka kedua metode tersebut layak untuk digunakan.

\section{DAFTAR PUSTAKA}

Cristiani I. dan Satyahadewi N. 2016. Peramalan Produksi Kelapa Sawit Pada PT. Perkebunan Nusantara XIII Dengan Metode Dekomposisi. Bimaster. Vol. 5, No. 2:119-126

Fauzi, Y., Y.E. Widyastuti., I. Satyawibawa., dan R.H. Paeru. 2014. Kelapa Sawit. Jakarta: Penebar Swadaya.

Firmansyah, M. A. 2014. "Karakterisasi, Kesesuaian Lahan dan Teknologi Kelapa Sawit Rakyat di Rawa Pasang Surut Kalimantan". Jurnal Pertanian Terapan, Vol. 14, No. 2: 97-105.

Gaspersz, V. 2011. Production Planning and Inventory Control Berdasarkan Pendekatan Sistem Teintegrasi MRP II dan JIT Menuju Manufakturing 21. Jakarta: Gramedia Pustaka Utama.

Gulo. 2014. Metodelogi Penelitian. Jakarta: Grasindo.

Hudori M. 2016. Perencanaan Kebutuhan Kendaraan Angkutan Tandan Buah Segar (TBS) di Perkebunan Kelapa Sawit. Malikussaleh Industrial Engineering Journal. Vol. 5, No. 1:2227.

Hudori M. dan Sugiyatno. 2015. "Analisis Akar Penyebab Masalah Variabilitas Free Fatty Acid (FFA) pada Crude Palm Oil (CPO) di Pabrik Kelapa Sawit". Operational Excellence-2nd, 185-192.

2016."Perbandingan Peramalan Produksi yang dikombinasikan dengan Seasonal Index dan Metode Black Bunch Cencus Untuk Estimasi Tandan Buah Segar Kelapa Sawit". Jurnal Citra Widya. Vol. 8, No. 3:189-199.

Kiswanto. 2008. Teknologi budidaya kelapa sawit. Jakarta: Badan penelitian dan pengembangan pertanian.

Miranda R. 2009. Manajemen panen Tanaman Kelapa Sawit (Elaeis
Guineenses Jacq.) di PT. Gunung Keemasan. Bogor: Departemen Agronomi dan Hortikultura Fakultas pertanian Bogor.

Mongoensoekarjo dan Semangun. 2008. Manajemen agribisnis kelapa sawit. Cetakan pertama. Yogyakarta: Gajah mada universitas press.

Prasetyo, E.I. 2009. Analisis Hubungan Curah Hujan dan Produksi Kelapa Sawit dengan Model Fungsi Transfer. Skripsi Departemen Statistika, Fakultas Matematika dan IImu Pengetahuan Alam, Bogor: Institut Pertanian Bogor.

Nazir M. 2013. Metode Penelitian. Bogor: Ghalia Indonesia.

Qomariah dan Gusti. 2019. "Estimasi Produksi Tandan Buah Segar Kelapa Sawit (Elaeis Guineensis Jacq) di PT. Basnur Citra Terpadu". Jurnal Online. Vol. 7, No. 2:1-5.

Simanjuntak, L. 2014. "Pengaruh Curah Hujan dan Hari Hujan Terhadap Produksi Kelapa Sawit Berumur 5, 10 dan 15 Tahun di Kebun Begerpang Estate PT. PP London Sumatra Indonesia, Tbk". Jurnal Online Agroekoteknologi, Vol. 2, No: 3:11411151.

Supranto. 2000. Teknik Sampling Untuk Survey Dan Eksperimen. Jakarta: Rineka Cipta.

Sugiyono. 2014. Metode Penelitian Pendidikan Pendekatan Kuantitatif, Dan R\&D. Bandung: Alfabeta. 